\title{
Empirical Literature on the Business Pitch: Classes, Critiques and Future Trends
}

\author{
Omar Sabaj ${ }^{*}$, Paula Cabezas ${ }^{1}$, Germán Varas $^{2}$, Carlos González-Vergara ${ }^{2}$, Álvaro Pina-Stranger ${ }^{3}$
}

\begin{abstract}
The growing importance of entrepreneurship and innovation for economic growth has propitiated a discursive genre that nowadays is almost omnipresent, i.e., the pitch. As with other emerging genres used in professional settings (e.g., selling presentations, business plans, etc.), several instructional discourses regarding the pitch have come out in the form of manuals and courses offering training on "how to make a pitch more powerful". Empirical research, however, is less common. The aim of this paper is to qualitatively review and sort out the existing empirical research on the pitch. For this, three classifying categories are proposed according to its reception (mainly by investors), the focus on discursive features, and its evolution. Finally, some critiques to the empirical research on the pitch and a description of some future trends on the field are provided. This work may be useful for professionals interested in innovation and entrepreneurship, areas in which this emerging discourse broadly circulates.
\end{abstract}

Keywords: business pitch; innovation discourse; innovation genres.

Submitted: May $8^{\text {th }}, 2019$ / Approved: March $9^{\text {th }}, 2020$

\section{Introduction}

Pitch is a highly polysemic term since it is used with diverse meanings in a wide variety of areas. In the academic context, for example, pitch is a short-time instance in which Ph.D. students (as well as more experienced scholars) describe and justify their research to other colleagues. In the world of business specifically, pitch often means a unique opportunity in which entrepreneurs describe their innovative ideas and try to obtain founding from possible collaborators, investors or clients. The term, according to Elsbach (2003) and Edmiston (2016), gained popularity in the Hollywood context where screenwriters had to persuade movie producers to take part of a film project. Since then, pitching has become a sort of omnipresent practice in the world of innovation, entrepreneurship and business, and currently, it has become the center of many business TV shows, such as The Pitch (USA, CL), Dragons' Den (UK, CA), or Shark Tank (USA and LATAM), among others.

Pitch has been usually defined using the baseball pitcher metaphor (Belinsky \& Gogan, 2016) and the elevator pitch cliché (Denning \& Dew, 2012). The baseball metaphor supposes a person (the entrepreneur) throwing an idea (pitching) to a specific audience (stakeholder) (Belinsky \& Gogan, 2016). The elevator pitch cliché, on the other hand, represents the idea of an oral presentation occurring in the time lapse of an elevator ride (e.g., from the first until the tenth floor), in which an innovator has to be able to sell his or her idea to an investor on such a short time (Denning \& Dew, 2012). As we will try to demonstrate, these metaphor and cliché fall short to describe what a pitch really is. For a more detailed characterization, pitch will be approached as a genre, which implies, basically, identifying its participants and purposes.

The general objective of this research is to provide a panoramic review of the academic literature, specifically empirical works, in which Pitch is analyzed as genre. To achieve that general goal, three specific objectives were proposed: a) to delineate some general attributes of the pitch literature, differentiating instructional discourse from academic sources; b) to explore how this emerging genre is defined and named as a class in the academic literature; and c) to offer a classification for empirical studies on the pitch. This review contains an up to date and comprehensive set of data, which may be useful for both experts in business, entrepreneurship and innovation, and those interested in understanding how language is used in professional settings. Finally, some critics and future trends in the study of pitch as a discursive genre are provided.

\section{Genres, classes and artifacts}

The pitch as text is tackled here as genre. Genre is one of those terms that have shed ink (and blood) from many scholars probably since Aristotle. This concept usually refers to a more or less stable set of statements associated to a social domain (Bajtín, 1979). More recent theory development has considered genres from a more dynamic perspective, for instance, as a) a frame, i.e. a matrix for ideas, b) a standard, i.e. a rhetorical and social schema shaping attitudinal behavior, c) a biological entity, i.e. an organism that evolves, spreads and fall in disuse, d) a family, i.e. genres possess a genealogical history, e) an institution, as they are part of a chain of values, and f) speech acts, since specific audiences are addressed through particular rhetorical moves (Swales, 2004).

For Bazerman (2013), genres are ways of doing things, and as such they embody actions, forms and the time in which they are carried out. Thus, genres have a socio-cognitive dimension in which participants of a rhetoric action can recognize the conventions of the rhetoric situation. In this sense, based on their experience, people have the ability to classify and denominate the different social actions in which they are involved by means of classes of genres, i.e. the name users give to these actions (Ciapuscio, 1994).

(1) Departamento de Artes y Letras, Universidad de La Serena, La Serena, Chile.

(2) Facultad de Letras, Pontificia Universidad Católica de Chile, Av. Libertador Bernardo O’Higgins 340, Santiago, Chile.

(3) Centre de recherche en économie \& management, Univesité de Rennes 1, Rennes, France.

*Corresponding author: omarsabaj@userena.cl

ISSN: 0718-2724. (http://jotmi.org)

Journal of Technology Management \& Innovation (c) Universidad Alberto Hurtado, Facultad de Economía y Negocios. 
Genres, like organisms (as proposed by Swales, 2004), are highly dynamic as they evolve in time. This evolution may be studied as a macroscopic longue dureé expression of culture or as a microscopic dimension intended to account for its ongoing transformation on specific settings (Spinuzzi, 2003). Analyzing an action or genre requires, among other procedures, identifying and describing its discursive features. In the action of pitching, specifically, sub-actions (e.g., narrating a catching story, demonstrating a certain function or describing the capacities of team members) play a significant role.

Other important component of a genre is its purpose (Swales, 2004). Although purposes of genres may be abstracted in a few Aristotelian categories derived from the three prototypical genres (i.e., forensic, deliberative and epideictic), there are as many objectives as there are social interactions. Thus, analyzing the purposes of genres sheds light on how these social actions work.

Genres instantiate in prototypical semiotic modes of expression. For example, novels are more likely to be written while parliamentary discussions tend to be oral. Genres, however, may integrate more than one semiotic mode as is the case of the pitch, in which participants may use different artifacts as meaning-making devices, such as slides decks, videos, graphics, business model diagrams or the product itself. Thus, for a discourse analysis, pitches can be studied according to both the semiotic mode, i.e. between-modes (intersemiotically) and within-mode (intrasemiotically), and the text focus, i.e. between-texts (intertextually) and within-text (intratextually) (Bednarek \& Caple, 2017).

Lastly, genres can be considered according to the characteristics of the actors that take part of the social interaction. This dimension of a genre refers to the number of participants (e.g. one to one, one to many, etc.), the roles they assume (e.g. the teacher/student), their mutual knowledge (e.g. close or unknown), and the power or the relationship among them (e.g. boss/worker, pitcher/investors, mother/son).

\section{Methods}

This research used a qualitative design. We conducted a bibliographical review analysis combined with content analysis to answer the following questions: 1 . What are the general attributes of the literature regarding the pitch? 2. How is the pitch defined and named in academic literature? 3. How can empirical studies be classified? To face these questions, we used different intended samples.

To answer question 1, bibliographical sources (research articles) were explored in the mainstream databases, using the strings "Pitch", "business pitch", "entrepreneurial Pitch", "innovation pitch", "sales pitch", "venture pitch", "elevator pitch", and "pitch/slide deck", from year 2000 onwards. After processing a first collection of 36 articles and considering their relevant references, other works on pitch were tracked. From this second search, older studies as well as articles related to "oral presentations", "techno-pitch", and "crowd-founding pitch" were included. In this first step we collected 43 sources, which were further restricted.
To answer question 2, we explored which of these 43 sources defined a pitch, classified it, and determined their purposes and their participants. Twelve of these sources presented a definition of the pitch class (see Table 1), and eleven of them (see Table 2) explicitly contained the purpose of the pitch.

To answer question 3, we identified which of the works in the initial sample (43) contained empirical data. Twenty-three article were found (see Table 3). Three of the authors (PC, OS, GV) analyzed together part of the empirical researches on the pitch to create classifying categories. Then, each observer independently classified all the studies using those categories. The few differences regarding the category denomination and case adscription were resolved by majority. This three-category model was validated by the rest of the authors. These categories will be presented in the Results section.

It is worth noting that the size of the data used to answer each question was not exclusive (i.e. data for each question was not summative). When initially exploring the literature, we found that some studies were purely instructional (relevant for question 1), and contained definitions, as well as the purpose of the genre (relevant for question 2), but they were not empirical research, so they could not be used to answer question 3. Conversely, there were cases of empirical works which did not present any definition of the genre investigated.

All the works from the initial sample (43), which neither presented a definition nor considered empirical data, were discarded. Although a sample of 23 articles is not big enough to generalized results, these data are well qualitatively representative of what is being researched on this topic.

\section{Results and discussion}

This section follows the same order of the objectives and the research questions. First, some findings and considerations of the data comprising the pitch studies of our sample are presented. The second part addresses the diversity of definitions, classes, and purposes attributed to this prototypical entrepreneurial genre. In the third part, categories, groups, and comments on specific works are provided. After presenting our classification of empirical research, we offer some of our critiques of the investigations on pitch and give some insights of how we visualize the future research on this genre.

\section{Identifying focuses, definitions and purposes of pitch}

The literature analysis revealed that most studies were focused on the "How to" rhetoric or, technically speaking, on their instructional or procedural features (Parodi, Ibañez \& Venegas, 2007). Among these studies, several articles propose methods to create and make an effective pitch (Elsbach, 2003; Edminston, 2016; Verma, Mohammed \& Bhargava, 2016; Mas \& Hsueh, 2017; Rusko, Lindholm, Petäjäniemi, 2016) and provide new formats for the pitch itself (Díaz, 2009; McCollough, Devenzer \& Tanner, 2016; Daly \& Davy, 2016b), usually offering tips for the reader on how to make a good pitch. Also, the review showed that some empirical research (see next section) were 
based on data collected from TV shows. Daly and Davy (2016a; 2016b), for example, analyzed pitches from the Dragon's Den while Moreau (2018) explored pitches from its American counterpart, Shark Tank.
The revision revealed that researchers (Denning \& Dew, 2012; McCollough, Devezer \& Tanner, 2016; Daly \& Davy, 2016a) usually claim that a considerable part of the definitions of pitch come from nonacademic sources, mainly, written press, websites, and TV Shows. Based on the literature review, Table 1 presents classes of pitch and their definitions.

Table 1. Pitch classes definition

\begin{tabular}{|c|c|c|}
\hline Class of pitch & Definition & Reference \\
\hline \multirow{4}{*}{ Pitch } & $\begin{array}{l}\text { The name of this genre -the pitch-suggests that the genre's function is fittingly unders- } \\
\text { tood through a baseball metaphor, wherein a pitcher throws a pitch to a catcher. Ac- } \\
\text { cording to this metaphor, the entrepreneur functions as the pitcher and is tasked with } \\
\text { establishing the momentum behind and control over the pitch. The catcher represents } \\
\text { the audience to whom the pitcher pitches -those stakeholders who catch-on to the pitch } \\
\text { and, ideally, are receptive to the innovation. The pitch itself, is fast, lasting between } 2 \text { and } \\
20 \text { minutes. }\end{array}$ & Belinsky and Gogan (2016, p. 323) \\
\hline & $\begin{array}{l}{[\ldots] \text { an oral presentation of a market opportunity to prospective business partners, typi- }} \\
\text { cally accompanied by a presentation slide deck. }\end{array}$ & Spinuzzi et al. (2014, p. 160) \\
\hline & $\begin{array}{l}\text { A pitch, like its supergenre, the proposal, is a 'bridge' genre or boundary object that con- } \\
\text { nects two different entities; its core argument defines a common interest that can serve as } \\
\text { a basis for exchanging things such as resources, services, expertise, and access. }\end{array}$ & Spinuzzi et al. $(2015$, p. 3$)$ \\
\hline & $\begin{array}{l}\text { These presentations [the pitch], which typically last between } 15 \text { and } 30 \text { minutes [...] the } \\
\text { most common objective of these presentations is for the entrepreneurs to successfully } \\
\text { persuade investors in their audience to 'get their bums off their seats' (as one pitch pre- } \\
\text { sentation skills consultant put it to the author), request a copy of their business plan and } \\
\text { agree to a subsequent meeting to discuss their investment opportunity in greater detail. } \\
\text { [These presentations] take the form of one - to five-minute 'rocket' or 'elevator' pitches, } \\
\text { are almost always delivered at an early, 'pre-contact' stage of the investor decision-ma- } \\
\text { king process - often before investors have met entrepreneurs or seen their business plan. }\end{array}$ & Clark (2008, p. 257) \\
\hline \multirow{4}{*}{ Elevator Pitch } & $\begin{array}{l}\text { The elevator pitch, sometimes known as the elevator speech, is a short summary that } \\
\text { quickly defines a product or service and its value proposition. [...] The pitch is usually } \\
\text { approximately } 30 \text { seconds, never more than two minutes. }\end{array}$ & Denning and Dew (2012, p. 38) \\
\hline & $\begin{array}{l}\text { An elevator pitch is a ubiquitous, time-tested tool to create a strong first impression, } \\
\text { opening doors to future dialogue and opportunities for advancement. }\end{array}$ & $\begin{array}{l}\text { Verma, Mohammed, and Bhargava (2016, } \\
\text { p. 716) }\end{array}$ \\
\hline & $\begin{array}{l}\text { An elevator pitch is a six-to-60-second invitation to learn more about a product or ser- } \\
\text { vice. }\end{array}$ & $\operatorname{Diaz}(2009$, p. 1) \\
\hline & $\begin{array}{l}\text { An elevator pitch is a compelling short story about who you are and what you are offe- } \\
\text { ring. A pitch should be no more than } 60 \text { seconds and might be as brief as } 6 \text { seconds. }\end{array}$ & $\operatorname{Diaz}(2009$, p. 2$)$ \\
\hline Entrepreneurial Pitch & $\begin{array}{l}\text { The entrepreneurial pitch is a brief description of the value proposition of an idea or } \\
\text { Company which entrepreneurs use to present ideas to potential equity shareholders such } \\
\text { as business angels and venture capitalists in the hope of securing the requisite equity } \\
\text { of strategic partners for their business. The pitch can last between } 30 \text { seconds and two } \\
\text { minutes. }\end{array}$ & Dale and Davy (2016a, p. 121) \\
\hline Business Pitch & $\begin{array}{l}\text { The business pitch represents efforts on the part of an entrepreneur (i.e., the pitcher) to } \\
\text { entice an investor (i.e., catcher) to provide resources (e.g., capital). }\end{array}$ & $\begin{array}{l}\text { Pollack, Rutherford, and Nagy (2012, p. } \\
916)\end{array}$ \\
\hline \multirow[t]{2}{*}{ Venture Pitch } & $\begin{array}{l}\text { The venture pitch is a communicative interaction in which entrepreneurs make a formal, } \\
\text { oral, persuasive appeal (often delivered with some sort of technical demonstration or } \\
\text { slide show graphics) to potential investors with the goal of securing investment funding } \\
{[\ldots]}\end{array}$ & Lucas et al. (2016, p. 365$)$ \\
\hline & Formal presentation leading to a request for funding & O’Connor (2002, p.93) \\
\hline Crowdfunding Pitch & $\begin{array}{l}\text { The crowdfunding pitch consists of information such as a general synopsis of the pro- } \\
\text { duct or service for which funding is being sought, the background of the management } \\
\text { team, and the funding-reward structure. This information is then overlaid into a 'virtual- } \\
\text { funding page' within the online crowdfunding platform, which generally consists of both } \\
\text { digital video and written text mediums used to convey the pitch. Unlike traditional forms } \\
\text { of funding, which often provide capital for 'general' purposes, crowdfunding is generally } \\
\text { sought for a specific purpose. }\end{array}$ & Davis et al. (2017, p. 92$)$ \\
\hline Techno Pitch & $\begin{array}{l}\text { A techno-pitch is a conscientious method of using social networking sites (SNSs) to find } \\
\text { and develop relationships with people or organizations who might become collaborators, } \\
\text { investors, or customers. }\end{array}$ & $\operatorname{Diaz}(2009$, p. 1$)$ \\
\hline
\end{tabular}


Since classes of genre correspond to the names and definitions given by the users (in this case, researchers typically coming from the business communication field), there was an overlap of classes and/or definitions. For instance, the terms 'Pitch' (Spinuzzi et al. 2014), 'Entrepreneurial Pitch' (Dale \& Davy, 20016), 'Business Pitch' (Pollack, Rutherford \& Naggy, 2012), and 'Venture Pitch' (O’Connor, 2002) refer more or less to the same idea. However, classes might imply a slightly different definition, and although authors sometimes propose a name for a given class, they do not always define it (e.g., Parhankangas and Renko, 2017).

Each class and definition may vary according to the elements emphasized, ignored or added in the name. For example, some names of classes highlight the setting or the purpose in which the pitch occurs, such as 'Entrepreneurial Pitch,' 'Business Pitch', and 'Crowdfunding Pitch". These three terms emphasize the role of the person doing the pitch, the business plan and the platform used to introduce the pitch, correspondingly. Length is another important component of the pitch definitions shown in Table 1, as for 'Elevator Pitch', 'the Pitch', and, to a lesser extent, the 'Entrepreneurial Pitch'.

Duration, in particular, is a fundamental aspect of the Elevator Pitch as shown in all definitions reviewed (Diaz, 2009; Denning \& Dew, 2012; Verma, Mohammed \& Bhargava, 2016). Different classes can be found according to duration: a) with more or less the same short duration ranges, such as 'Elevator Pitch', ranging from 6 seconds to 2 minutes (Diaz, 2009; Denning and Dew, 2012)); or 'Entrepreneurial Pitch', ranging from 30 seconds to 2 minutes (Dale and Davy, 2016a); and b) others varying much more, such as "Pitch", ranging from 2 to 20 minutes (Belinsky \& Gogan, 2016) or from 15 to 30 minutes (Clark, 2008).

Semiotic modes of expression were explicitly present in three definitions. Two of them, explicitly refer to the oral nature of the pitch (Spinuzzi et al., 2014; Lucas et al., 2016). In the case of the "Crowdfunding Pitch", Davis et al. (2017) specify the visual and written modes of expression for this specific genre. All other definitions of the pitch include the word "presentation", which implicitly refer to the oral nature of this genre.

As for the pitch participants, they are mainly two (Spinuzzi et al. 2015). From the side of the speaker, the main role in every definition is that of 'Entrepreneur'. It is interesting to note that this role is supposed to be performed by a single individual. From the side of the audience (assumed to be collectively performed), the roles are more varied, e.g. 'investors', 'prospective business partners', and 'stakeholders who catch-on and ideally are receptive to innovation', 'business angels', or 'venture capitalists.

It is worth noting that the relation between the speaker and the audience is asymmetrical in terms of power. The audience, on the one hand, has the capacity to invest or not in an entrepreneur while the speaker, on the other, is expected to have more knowledge about the business than the audience.

As for purposes, Table 2 zooms in on Table 1 to show the ones attributed to the different classes of pitch.

Table 2. Purposes in pitch definitions (slightly adapted)

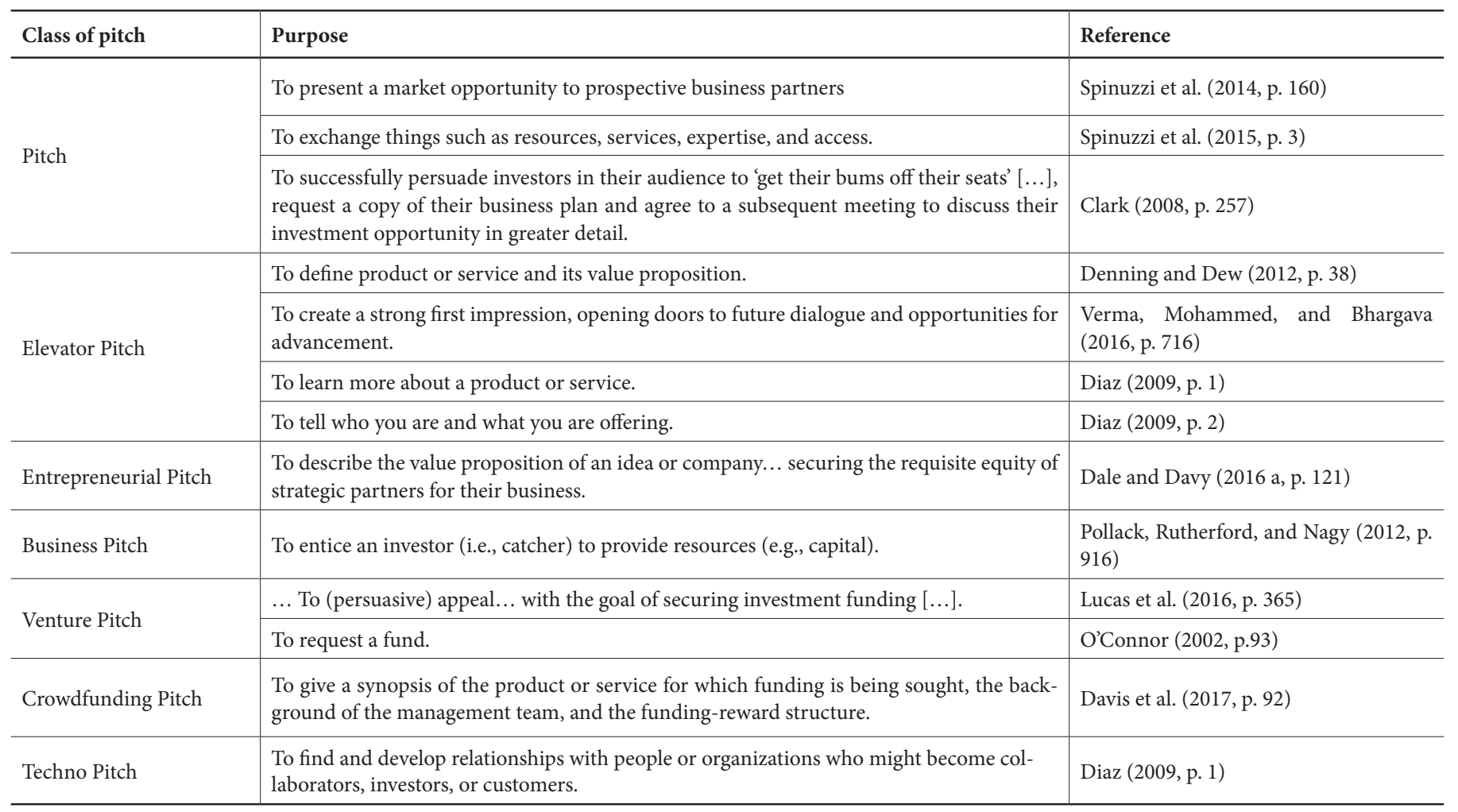


Purposes in Table 2 were slightly adapted from the definitions of Table 1 using the infinitive. Independently of the class, funding request is a transversal purpose attributed to the pitch. But funding is not the only request since entrepreneurs also need to obtain intangibles from investors, such as networks, expertise, access, and market knowledge (Spinuzzi et al. 2015).

Some of the purposes of Table 2 emphasize the persuasive nature of the pitch (Clark, 2008; Verma, Mohammed, \& Bhargava, 2016; Pollack, Rutherford, \& Nagy, 2012, Lucas et al., 2016). This genre attribute is expressed in sequences such as 'To successfully persuade investors [...] to 'get their bums off their seats'; create a strong first impression, to entice an investor, persuasive appeal' (Clark, 2008). Other definitions, on their side, are more technical and neutral, and less interactive. The persuasive/neutral dichotomy is important since it determines the definition and the expected effect of pitch.
There are two definitions (Clark, 2008; Verma, Mohammed, \& Bhargava, 2016) in which the purpose is linked to an early stage in the interaction of the entities that take part of the pitch. The aim is to convince the other party of having a future encounter. All other purposes of the pitch classes in Table 2 are not related to any specific stage in the development of a project, a technology or a service. As we will argue, exploring this interaction (purposes of the pitch and the phase of the business) can be useful to better understand how the social action of a pitch works.

\section{Three types of empirical literature on the pitch}

When proposing a classification, categories are often forced to be exclusive, i.e. with sharp and recognizable limits. However, this is not always possible since concepts using natural language have imprecise and fuzzy borders that make them true or false only to a certain extent (Lakoff, 1972). Thus, types of research were assumed to have fuzzy limits. Table 3 shows types, definitions of each type of study and all corresponding sources.

Table 3. Three types of empirical literature on the pitch

\begin{tabular}{l|l|l}
\hline Type & Definition & Sources \\
\hline $\begin{array}{l}\text { A. Reception } \\
\text { studies }\end{array}$ & $\begin{array}{l}\text { This type of investigation is aimed at exploring the effect of different elements of the } \\
\text { pitch in an audience, such as the act of pitching itself, the pitcher, the pitcher's attributes, } \\
\text { the value proposition, the business plan, and the venture, among others. }\end{array}$ & $\begin{array}{l}\text { (MacMillan, Siegel \& Narasimha, 1985; MacMillan, } \\
\text { Zemann \& Narasimha, 1987; Mason \& Harrison, } \\
\text { 2003; Clark, 2008; Pollack, Rutherford \& Nagy, } \\
\text { 2012; Lucas, Kerrick, Haugen \& Crider, 2016; Ciu- } \\
\text { chta, Letwin, Stevenson, McMahon \& Huvaj, 2018; } \\
\text { Davis, Hmieleski, Webb \& Coombs, 2017) }\end{array}$ \\
\hline $\begin{array}{l}\text { B. Linguistic } \\
\text { and discursive } \\
\text { features }\end{array}$ & $\begin{array}{l}\text { This type of studies focuses on the description of linguistic or discursive features of the } \\
\text { pitch or on the artifacts used (e.g., slide desks). }\end{array}$ & $\begin{array}{l}\text { (Blazkova, 2011; Cunningham, 2010; Daly \& Davy } \\
\text { 2016a; Daly \& Davy 2016b, Parhankangas \& Renko, } \\
\text { 2017; Moreau, 2018; van Werven, Bouwmeester \& } \\
\text { Cornelissen, 2019) }\end{array}$ \\
\hline $\begin{array}{l}\text { C. Process, evo- } \\
\text { lutionary, dialo- } \\
\text { gical research }\end{array}$ & $\begin{array}{l}\text { This type of research is oriented to understanding how a pitch evolves in a time span as } \\
\text { a result of the interaction with other actors and genres. }\end{array}$ & $\begin{array}{l}\text { (Belinsky \& Gogan, 2016; O, Connor, 2002; Spi- } \\
\text { nuzzi et al., 2014, 2015a, 2015b; Spinuzzi, Jakobs \& } \\
\text { Pogue, 2016a; Spinuzzi et al.2016b; Spinuzzi et al., } \\
\text { 2018) }\end{array}$ \\
\hline
\end{tabular}

The three types of empirical literature on the pitch are different not only in their approach to their object of study, but also in the theories, methods, and background disciplines of the researchers who investigate it. Chronologically speaking, reception studies are the pioneers. In fact, classical work by MacMillan, Siegel and Narasimha (1985; MacMillan, Zemann \& Narasimha, 1987) did not even use the word pitch. These studies are typically conducted by business and management academics interested in venture capitalists' criteria (or investors in general) for (not) funding a business idea. Among these researchers, questionnaires, interviews, surveys, as well as certain quantitative approaches to data, are the common techniques for data collection. As shown in Table 3, reception studies may focus on aspects of the business plans, but also, and especially, on some characteristics of the pitcher, such as preparedness, passion, product creativity, and market knowledge (Lucas et al., 2016). Most of these studies conclude that the pitcher attributes are crucial determiners that influence the investors' decision.

Researches in the group B focus on describing linguistic and discursive features of the pitch as a genre (and description of artifacts may be found). Most of these studies use a qualitative approach to identify and characterize attributes in a variety of levels, ranging from lexical, semantic and discursive dimensions of language use. Consistently with this type of research, the theoretical and methodological background of the authors belongs to humanities, specifically, linguistics and discourse analysis.

Cunningham (2010) is a good example of this linguistic approach. She made a noun-to-verb count, a syntax analysis, and an examination of the metaphors to determine what distinguishes a winning pitch from a losing one. She concluded that noun-to-verb ratio has little impact on the success of a presentation. In addition, she revealed that short sentences are more appealing than long ones although there was not a strong difference since simple sentences were mostly used. Finally, she noticed that winning pitches tend to include a higher number of metaphors than the less successful ones, concluding that metaphors are a fundamental part of persuasion and, therefore, a key aspect of the pitch.

In this same group of works, Daly and Davy (2016a, b) conducted a multilevel analysis of a wide variety of linguistic features. In their work (2016a), they identified 10 stages or rhetorical structures of the 
pitch. Based on these discoveries, they created the "investor pitch process model" (2016b) aimed to help entrepreneurs create their own pitches by having a clearer vision of the expected structures and rhetoric. A similar approach was found in Parhankangas and Renko (2017), who analyzed over 600 Kickstarter campaigns in order to determine how the linguistic style of a pitch can account for the success of new social ventures. Their results show how the use of precise and interactive language equals higher amounts of funding for social ventures.

The third group labelled with letter $\mathrm{C}$ in Table 3 includes studies aiming at understanding the process of elaborating a pitch as its value propositions evolve in time. Although these investigations may track some linguistic and discursive features (type B), they are used as proxies to describe how the pitch evolves in business accelerators' programs. The investigations comprising this category are dialogical and (socio)constructivist in the sense that pitch is understood to be a co-creation between pitchers, investors, and mentors (Spinuzzi et al., 2014). In these approaches, pitch is usually considered to be influenced by other genres and artifacts within an ecology of genres (Spinuzzi, 2003). For eliciting data, these studies use ethnographic, anthropological and cultural techniques, such as the analysis of decks, in-depth interviews with pitchers, investors and mentors, use of field notes, audio recording and videotaping.

Spinuzzi (2014, 2015a, 2015b, 2016a, 2016b, 2018) analyzed the transformations of a pitch as contestants receive feedback in competitions or evaluation settings. To identify changes, Spinuzzi et al. (2014, 2015a, 2015b) focused on the pitch deck, a set of slides that are usually used along the oral presentation. They collected and contrasted decks presented in different moments of a competition, i.e. before and after the business teams received feedback from judges and trainers and analyzed changes in the general structure of the presentation and the individual slides (Spinuzzi et al., 2014, 2015b). In these studies, they identified different aspects that were related to the modification of desks, such as the reuse of material from other documents (Spinuzzi et al., 2015a) and the feedback received from reports, judges and trainers (Spinuzzi et al., 2015b, 2016b). Spinuzzi et al. (2016a) classified these transformations in three types, those transforming the innovators, the innovations, and the innovators' cultural understanding. These studies showed the relation between the pitch and other genres used in entrepreneurship and innovation, and the importance of crafting a pitch that can fit in those genres. Spinuzzi et al. (2018) showed the evolution of value propositions in a student accelerator program. In this and others works, Spinuzzi and colleagues analyzed the claims made by entrepreneurs when presenting a value proposition.

O'Connor (2002) and Belinsky and Gogan (2016) are also good examples of this type of research (group C). In her study, O'Connor (2002) followed the changes of a high-tech start-up and typified the narrative used by its founder to confront the dot-com crash of the early 2000s. For this, O'Connor (2002) revealed how the founder changed his pitch to build a credible story, starting with a narrative of pure heroism and vision, and closing with one of market and profit. Belinsky and Gogan (2016), on their part, conducted an auto-ethnography to analyze the experience of the first author as a participant of pitch competitions. They concluded that stakeholders' feedback can heavily influence entrepreneurs' frames.

\section{Some critiques to the empirical research on the pitch}

In this section, we propose some general critical observations on the research of the pitch. First, as already mentioned above, not every empirical research use data collected from real settings, but from TV programs. Although useful, this kind of information implies a number of challenges and considerations. For example, data are shaped by the norms and the rules of TV shows, which often make the practice of pitching look like invariable. Thus, this should be a caveat for the reader before interpreting and valuing research results obtained from TV shows. Also, most of the reviewed literature showed that pitching is about performing, acting and convincing audiences, thus pitching is somehow like a spectacle in which performing is essential. In this sense, a relation between pitching and TV show formats is expected.

Secondly, all research, except that of group C, assumes that the pitch is a sort of diva, a linchpin genre. This consideration is usually evidenced when pitch competences are flamboyantly presented on TV. According to Spinuzzi (2003), there are no linchpin genres since in every activity there is always a genre ecology, i.e., a group of genres influencing and interacting with each other. In this sense, pitch is a false diva.

Thirdly, the analysis of pitch demands researchers to think of the unit of analysis. As described before, the prototypical mode of expression of the pitch is oral, but this genre is typically performed along with other artifacts, such as slide deck, music, video, photos, and so on. Thus, some questions arise: what do we study when we face a pitch? Should we study the verbal and no verbal characteristics of the presentation? Should we consider describing the artifacts used together with the pitch, e.g., slide decks, written texts and/or images?

As evidenced in the review, in most of the literature the former questions are not explicitly addressed. In fact, while groups B and C take pitch itself (as well as artifacts) as their object of study, most of articles of group A only focused on the effect of the pitch (in terms of how investors evaluate the value proposition of a business idea) to understand the potential quality of a venture.

Fourthly, there is a lack of integration of the different research methodologies. Only recently, studies of group $\mathrm{C}$ have shown some interdisciplinary approaches to the description of this genre, which is consistent with the multi-theoretical backgrounds of the authors. Spinuzzi et al. (2018), for example, using categories from the sociology of translation (Callon, 1986), studied the different stages of a pitch, such as problematization and interessment (centered on the ability of the entrepreneurs), and enrolment or mobilization (centered on the investor's behavior according to the entrepreneur's expectations). As we will try to show in the next section, there is currently plenty of space for multifaceted research endeavors. 
Finally, there are good reasons to believe that the metaphor of the pitcher and the cliché of the elevator pitch are not adequate neither to understand nor to teach this genre. Even though there are several reasons that explain the relation between pitch and baseball, since this sport is only played in a few countries its contribution as a universal didactic explanation is restricted beforehand. Besides, the metaphor implies that the catcher is a passive actor, contradicting the purpose of making people invest in a venture or, as Clark (2008, p. 257) puts it, "get their bums off their seats'; in other words, a good pitch should make people react, not remain passive. Similarly, the elevator pitch cliché does not allow to understand this genre since short duration is not a transversal attribute. However, it is still used as a universal formula for training pitch despite the fact that it describes a very specific use of the genre (make contact in early stages).

\section{Concluding remarks and future trends}

In this paper, we have critically revised some definitions and purposes that the literature has attributed to the pitch. The variety of classes and the overlapping definitions and purposes have shown that this genre is still in an early and dynamic stage of stabilization.

All definitions analyzed include more or less the same interacting entities (i.e., entrepreneur and the investor), although the purpose of the interaction may present some variations. While some definitions focus on the action of the speaker, others focus on its purpose and its effect on the audience. Most of the research ignores the fact that the pitch is just a single genre within a bigger ecology where species interact and influence one another.

Our critical observations on the empirical literature prove that there are great opportunities to develop new lines of research, some of which are already emerging as previously seen among the studies of the group C. After our reviewing of the relevant literature on the pitch, we present four future trends, along with potential research questions, towards its investigation:

1. Interface research integrating the three types of research established in the present work. A relevant question is: Do the characteristics of the oral presentation, as the tone of the voice of the speaker or his/her non-verbal behavior, determine the reception of the pitch?

2. Research on the genre ecologies related to different stages of a business project, from early conception to product commercialization. Relevant questions are: How the genre ecology varies chronologically as the business develops over time? How does a pitch vary to achieve different purposes at different stages of an entrepreneurship?

3. Research including technology to measure neurophysiological responses of investors as they watch a pitch, for example, using bracelets or sensors that can feel heart beats, breathing intensity, blood flux, or the level of oxygen saturation, as indicators of investors engagement with a venture. What are the effects of the pitch? Is the business model more important than the potential revenue in terms of its impact (for example, the audience's attention)? What role does the charisma of the pitcher play in the presentation?

4. Longitudinal research in which the reception of an idea, the discursive features of the genre ecology developed along the project and the process of constructing the pitch will be associated with long term metrics or variables of success. What is the relation between the artifacts and the oral presentation? How does the pitcher construct her/his oral presentation? How does the pitcher design his/her slide decks?

These potential directions in the empirical research of the pitch mean promising opportunities to continue developing our understanding of this crucial genre that embodies innovation and entrepreneurial action.

Acknowledgements: The authors thank the Chilean National Fund for Scientific and Technological Development Fondecyt Grant Number 1170133

\section{References}

Bazerman, C. (2013). A Rhetoric of Literate Action: Literate Action Volume 1. Perspectives on Writing. Fort Collins, Colorado: The WAC Clearinghouse and Parlor Press.

Bajtín, M. (1979). Estética de la creación verbal. México: Siglo XXI.

Bednarek, M. \& Caple, H. (2017). The discourse of values. How news organization create newsworthiness. New York, United States: Oxford University Press.

Belinsky, S. \& Gogan, B. (2016). Throwing a Change-Up, Pitching a Strike: An Autoethnography of Frame Acquisition, Application, and Fit in a Pitch Development and Delivery Experience. IEEE Transactions on Professional Communication, 59(4), 323-341. https:// doi.org/10.1109/TPC.2016.2607804

Blazkova, H. (2011). Telling Tales of Professional Competence: Narrative in 60-Second Business Networking Speeches. Journal of Bussiness Communication, 48(4), 446-463.

Ciuchta, M. P., Letwin, C., Stevenson, R., McMahon, S. \& Huvaj, M. N. (2018). Betting on the Coachable Entrepreneur: Signaling and Social Exchange in Entrepreneurial Pitches. Entrepreneurship Theory and Practice, 42(6), 860-885. https://doi.org/10.1177/1042258717725520

Callon, M. (1986). Some elements of a sociology of translation: Domestication of the scallops and the fishermen of Saint Brieuc Bay. In J. Law (Ed.), Power, action and belief: A new sociology of knowledge? (pp. 67-83). Boston, MA: Routledge.

Clark, C. (2008) The Impact of Entrepreneurs' Oral "pitch" Presentation Skills on Business Angels' Initial Screening Investment Decisions. Venture Capital: An International Journal of Entrepreneurial Finance, 10(3), 257-279. 
Cunningham, L. (2010). A Linguistic Analysis of the Entrepreneurial Pitch (Master's thesis). Clemson University, Clemson, South Carolina, United States.

Daly, P. \& Davy, D. (2016a). Structural, linguistic and rhetorical features of the entrepreneurial pitch. Journal of Management Development, 35(1), 120-132. https://doi.org/10.1108/JMD-05-2014-0049

Daly, P. \& Davy, D. (2016b). Crafting the Investor Pitch Using Insights from Rhetoric and Linguistics. In G.M. Alessi \& G. Jacobs (Eds.), The Ins and Outs of Business and Professional Discourse Research. Reflections on Interacting with the Workplace (pp. 182-203). London: Palgrave MacMillan. https://doi.org/10.1057/9781137507686

Davis, B. C., Hmieleski, K. M., Webb, J. W. \& Coombs, J. E. (2017). Funders' positive affective reactions to entrepreneurs' crowdfunding pitches: The influence of perceived product creativity and entrepreneurial passion. Journal of Business Venturing, 31(1), 90-106. https:// doi.org/10.1016/j.jbusvent.2016.10.006

Denning, P.J. \& Dew, N. (2012). The Myth of the Elevator Pitch. Communications of the ACM, 55(6), 38-40. https://doi. org/10.1145/2184319.2184333

Diaz, C. (2009). Teaching the Techno-Pitch: Taking Student Innovators Beyond the Elevator Pitch. IEEE International Professional Communication Conference IPCC'2009. Available at http://ieeexplore.ieee.org/stamp/stamp.jsp?tp=\&arnumber=5208685\&isnumb er $=5208666$.

Edmiston, D. (2016). Developing the Perfect Pitch: Creating a Positive First Impression through Social Media. Marketing Education Review, 26(1), 3-7. https://doi.org/10.1080/10528008.2015.1091660

Elsbach, K. (2003). How to Pitch a Brilliant Idea. Harvard Business Review. Available at https://hbr.org/2003/09/how-to-pitch-a-brilliant-idea

Lakoff, G. (1972). Hedges: a study in meaning criteria and the logic of fuzzy concepts', Proceedings of the Chicago Linguistics Society 8, $183-228$.

Lucas, K., Kerrick, S. A., Haugen, J. \& Crider, C. J. (2016). Communicating Entrepreneurial Passion: Personal Passion vs. Perceived Passion in Venture Pitches. IEEE Transactions on Professional Communication, 59(4), 363-378. https://doi.org/10.1109/TPC.2016.2607818

MacMillan, I. C., Siegel, R. \& Narasimha, P. N. S. (1985). Criteria used by venture capitalists to evaluate new venture proposals. Journal of Business Venturing, 1(1), 119-128. https://doi.org/10.1016/08839026(85)90011-4

MacMillan, I. C., Zemann, L. \& Subbanarasimha, P.N. (1987). Criteria Distinguishing Unsuccessful Ventures in the Venture Screening Process. Journal of Business Venturing, 2(2), 123-137. https://doi. org/10.1016/0883-9026(87)90003-6
Mas, J. P. \& Hsueh, B. (2017). An Investor Perspective on Forming and Funding your Medical Device Start-Up. Techniques in Vascular and Interventional Radiology, 20(2),101-108. https://doi.org/10.1053/j. tvir.2017.04.003

Mason, C. \& Harrison, R. T. (2003). Auditioning for Money: What Do Technology Investors Look for at the Initial Screening Stage? The Journal of Private Equity, 6(2), 29-42.

McCollough, M. A., Devezer, B. \& Tanner, G. (2016). An alternative format for the elevator pitch. The International Journal of Entrepreneurship and Innovation, 17(1), 55-64. https://doi.org/10.5367/ ijei.2016.0211

Moreau, C.P. (2018). Discursive Diversity in the Entrepreneurial Pitch: Creating and Communicating a Marketplace Space (CAMS) in the High-Stakes Reality TV Show Shark Tank. Proceedings of the 83rd Annual International Conference Association for Business Communication at: Miami, Florida, USA

O'Connor, E. (2002). Storied business: Typology, Intertextuality, and Traffic in Entrepreneurial Narrative. International Journal of Business Communication, 39(1), 36-54. https://doi. org/10.1177/002194360203900103

Parhankangas, A. \& Renko, M. (2017). Linguistic style and crowdfunding success among social and commercial entrepreneurs. Journal of Business Venturing, 32(2) 215-236. https://doi.org/10.1016/j.jbusvent.2016.11.001

Parodi, G., Ibánez, R., \& Venegas, R. (2009). El Corpus PUCV-2006 del español: identificación y definición de los géneros discursivos académicos y profesionales. Literatura y lingüística, (20), 75-101.

Pollack, J. M., Rutherford, M. W. \& Nagy, B. G. (2012). Preparedness and Cognitive Legitimacy as Antecedents of New Venture Funding in Televised Business Pitches. Entrepreneurship Theory and Practice, 36, 915-939. https://doi.org/10.1111/j.1540-6520.2012.00531.x

Rusko, R., Lindholm, K. \& Petäjäniemi, S. (2016). Coopetition at Elevator Pitch Events? A Case Study of Micro-activities at a Business Innovation Event. Journal of Innovation Management, 4(3), 79-100.

Spinuzzi, C. (2003). Tracing Genres through Organizations: A Sociocultural Approach to Information Design. Cambridge, Massachusetts: The MIT Press.

Spinuzzi, C., et al. (2014). Making the Pitch: Examining Dialogue and Revisions in Entrepreneurs' Pitch Decks. IEEE Transactions on Professional Communication, 57(3), 158-181. https://doi.org/10.1109/ TPC.2014.2342354

Spinuzzi, C., et al. (2015a). Remaking the Pitch: Reuse Strategies in Entrepreneurs' Pitch Decks. IEEE Transactions on Professional Communication, 58(1). https://doi.org/10.1109/TPC.2015.2415277 
Spinuzzi, C., et al. (2015b). How Do Entrepreneurs Hone Their Pitches? Ponencia presentada en el 33rd ACM International Conference on Design of Communication, The University of Texas, Austin. https://doi.org/10.1145/2775441.2775455

Spinuzzi, C., Jakobs, E. \& Pogue, G. P. (2016a). A Good Idea is Not Enough: Understanding the Challenges of Entrepreneurship Communication. Ponencia presentada en el International Conference on Competitive Manufacturing, The University of Texas, Austin.

Spinuzzi, C., et al. (2016b). How Magnets Attract and Repel: Interessement in a Technology Commercialization Competition. Written Communication, 33(1), 3-41. https://doi.org/10.1177/0741088315614566
Spinuzzi, C., Altounian, D., Pogue, G., Cochran, R. \& Zhu, L. (2018). Articulating Problems and Markets: A Translation Analysis of Entrepreneurs' Emergent Value Propositions. Written Communication, 35(4), 379-410. https://doi.org/10.1177/0741088318786235

Swales, J.M. (2004). Research Genres: Explorations and Applications. Cambridge: Cambridge University Press.

van Werven, R., Bouwmeester, O. \& Cornelissen, J. P. (2019). Pitching a business idea to investors: How new venture founders use micro-level rhetoric to achieve narrative plausibility and resonance. International Small Business Journal, 37(3), 193-214. https://doi. org/10.1177/0266242618818249

Verma, N., Mohammed, T. \& Bhargava, P. (2016). 30 Seconds to Impact: Crafting the Perfect Radiology Elevator Pitch. Journal of the American College of Radiology, 14(5), 716-717. https://doi. org/10.1016/j.jacr.2016.11.017 